Article

\title{
A New Simulation Approach to Model Complex Fracture Networks in the Shale Formation Considering Gas Desorption
}

\author{
Xinfang Ma \\ MOE Key Laboratory of Petroleum Engineering, China University of Petroleum (Beijing), \\ Beijing 102249, China; maxinfang@cup.edu.cn
}

\begin{abstract}
Hydraulic fracturing in shale gas reservoirs has usually resulted in complex fracture network. The results of micro-seismic monitoring showed that the nature and degree of fracture complexity must be clearly understood to optimize stimulation design and completion strategy. This is often called stimulated reservoir volume (SRV). In the oil \& gas industry, stimulated reservoir volume has made the shale gas exploitation and development so successful, so it is a main technique in shale gas development. The successful exploitation and development of shale gas reservoir has mainly relied on some combined technologies such as horizontal drilling, multi-stage completions, innovative fracturing, and fracture mapping to engineer economic completions. Hydraulic fracturing with large volumes of proppant and fracturing fluids will not only create high conductivity primary fractures but also stimulate adjacent natural fractures. Fracture network forming around every hydraulic fracture yields a stimulated reservoir volume. A model of horizontal wells which was based on a shale gas reservoir after volume fracturing in China was established to analyze the effect of related parameters on the production of multi-fractured horizontal wells in this paper. The adsorbed gas in the shale gas reservoir is simulated by dissolved gas in the immobile oil. The key to simulate SRV is to accurately represent the hydraulic fractures and the induced complex natural fracture system. However, current numerical simulation methods, such as dual porosity modeling, discrete modeling, have the following limitations: 1) time-consuming to set up hydraulic and natural fracture system; 2) large computation time required. In this paper, the shape of the stimulated formation is described by an expanding ellipsoid. Simplified stimulated zones with higher permeability were used to model the hydraulic fracture and the induced complex natural fracture system. In other words, each primary fracture has an enhanced zone, namely SRV zone. This method saves much developing fine-grid time and computing time. Compared with the simulation results of fine-grid reference model, it has shown that this simplified model greatly decreases simulation time and provides accurate results. In order to analyze the impacts of related parameters on production, a series of simulation scenarios and corresponding production performance were designed. Optimal design and analyses of fracturing parameters and the formation parameters have been calculated in this model. Simulation results showed that the number of primary fractures, half length, SRV half-width and drop-down have great effects on the post-fracturing production. Formation anisotropies also control the production performance while the conductivity of the primary fractures and SRV permeability do not have much impact on production performance. The complexity of stimulated reservoir volume has strong effect on gas well productivity. Fracture number mainly affects the early time production performance. The increase of SRV width cannot enlarge the drainage area of the multi-fractured horizontal wells, but it can improve the recovery in its own drainage region. Permeability anisotropies have much effect on production rate, especially the late time production rate. The results prove that horizontal well with volume fracturing plays an irreplaceable role in the development of ultra-low permeability shale gas reservoir.
\end{abstract}

Keywords: shale gas; stimulated reservoir volume; fracture parameters optimization; formation parameters 


\section{Introduction}

Shale gas reservoirs have been the major target for economic development throughout the world owing to the progress in the fields of horizontal drilling and hydraulic fracturing (Yu et al., 2014). Shale gas has also become more and more important in the gas supply in North America and around the world. Shale gas reservoirs have their own distinctive characteristics. Shale-gas reservoirs are characterized by extremely low permeability, small grain size and porosity, and high total organic carbon (TOC). Its permeability ranges from 10 to 100 nanodacies, porosity ranging from $2 \%$ to $8 \%$. Shale gas reservoirs are rich in organic material, varying from one formation to another. And what differentiate shale from other conventional formations is that shale can serve as both reservoir rock and source rock (Martin et al., 2010). And gas in shale reservoirs is composed of both free gas in pores and fractures and adsorbed gas in organic matter. Hence, it is critical to investigate the mechanism of gas adsorption. Besides, for shale gas reservoir stimulation, modeling complex fracture network is also of great importance (Zhang et al., 2011).

According to previous micro-seismic monitoring (Cipolla et al., 2008), complex fracture system can be generated with the interaction of hydraulic fractures and pre-existing natural fractures and fissures. This complexity is a combination of many mechanisms, such as the existence of natural fractures, low stress anisotropy and the application of low viscosity fluid. As a result, a large stimulated reservoir volume (SRV) is created to enhance gas production rate (Guo et al., 2013; Mayerhofer, 2010). Maximizing this stimulated reservoir volume plays a vital role in shale gas reservoir development.

Given that the fracture complexity and SRV are main contributor of shale gas production, reservoir simulation is the commonly used approach for gas well performance evaluation and prediction. The conventional planar models are inadequate for the complex fracture system in shale gas reservoirs. Hence, how to simulate the complexity of fracture network is the major problem for reservoir simulation approach. A valid and accurate model is critical to sensitivity analysis of production to reservoir parameters.

In the last few years, many new hydraulic fracture models have been developed to address this problem (Fisher, 2004; Xu et al., 2009; Weng et al., 2011; Nagel et al., 2011; Fazelipour, 2011; McClure, 2012; ). Cipolla et al. (2010) pointed out that a proper and accurate model to simulate the complex fracture network must on one hand simulate fluid flow in the created fracture network and on the other hand take into consideration of the interaction between the fluid and the fracture width, as well as the interaction between the fractures. Analytical and semi-analytical approaches have been proposed to model the production of shale gas reservoirs. Xu et al. (2009a and 2009b) presented a semi-analytical model, namely the Wire-mesh model, which simulates orthogonal hydraulic fracture networks (HFN) during a fracturing stimulation treatment by a growing elliptic volume of the stimulated formation. It consists of two perpendicular sets of vertical planar fractures with average spacing. The model has been further improved to be capable of predicting the fracture height growth, proppannt placement as a function of time, and supporting variable pump schedules for fluid and proppant (Xu et al., 2010). Simulation based on the Wire-mesh model can provide HFN characteristics such as the proppant concentration and the fracture conductivity. And it can optimize treatment design and proppant placement to ensure maximum gas production. Besides, the model is also beneficial to determine where to distribute fracturing stages and perforation clusters. 
In order to simulate the interaction between a hydraulic fracture and a pre-existing natural fracture, Weng et al. (2011) proposed a more rigorous fracture simulator, referred to as the Unconventional Fracture Model (UFM), for complex interconnected fracture network. The model can simulate the propagation, deformation and one dimensional fluid flow in a complex fracture network. Fracture height growth is modeled as in conventional pseudo-3D models. For simulating proppant transport in the fracture network, the model uses a three-layer proppant-transport model, with clean fluid at the top, a slurry layer in the middle, and a proppant bank at the bottom. What makes UFM model distinct from Wire-mesh model is that it takes into account of the interaction of a hydraulic fracture tip with a pre-existing natural fracture when they intersect, for example whether the hydraulic fracture propagates through, or is arrested by the natural fracture when they intersect and whether it subsequently propagates along the natural fracture. While the model allows one to better match the observed micro-seismic survey and provide more accurate tool for fracture network geometry prediction, it still have many limitations. One of the limitations is that it demands more and better defined input parameters, and poses great challenge for engineers to use in a proper way.

Meanwhile, shale gas possesses the characteristic of free adsorption on surface areas associated with organic content and clay. Leahy-Dios et al. (2011) found out that gas in shale is present as free gas in both organic matter and larger pores and natural fractures, as well as absorbed gas in organic matter. It is believed that the adsorbed gas represents significant quantities of total gas reserves $(20 \%-80 \%)$ as well as recovery rates (Hill and Nelson, 2000), which cannot be ignored in any model. Total organic content (TOC) in shale and reservoir pressure are two important factors that affects total gas production. Thus, study of gas adsorption mechanism can provide insights to the well performance evaluation as well as the optimization of fracture design.

Many studies have proposed various mathematical models for adsorption with different assumptions. The most commonly used model to characterize the adsorption process is the classic Langmuir isotherm (Wei et al., 2014). It is assumed that there is only one single layer of molecules covering the solid surface and there is a dynamic equilibrium at constant temperature and pressure between adsorbed and non-adsorbed gas (Langmuir, 1918). Langmuir pressure and Langmuir volume are the two key parameters in this model. Langmuir volume is referred to as the gas volume at the infinite pressure representing the maximum storage capacity for gas; Langmuir pressure is the pressure corresponding to one-half Langmuir volume. At the same reservoir pressure, more adsorbed gas can be got at higher Langmuir pressure. The Langmuir isotherm is often determined in laboratory using core samples.

What's worth to mention is that it assumes the process of the gas desorption from matrix to fractures are instant when there are high conductivity fractures in shale, which means there is no transient lag between pressure drop and desorption response (Freeman et al., 2012). According to Gao et al., this assumption is reasonable considering flow through the kerogen is slow due to the ultralow permeability in shales. Based on this assumption of instantaneous desorption, Seidle and Arri (1990) developed an approach to model the effect of gas desorption from a coal bed methane reservoir in a black oil model in the simulator of CMG. Thus, conventional reservoir simulators can then be used for coalbed methane modeling purposes.

In light of the fracture parameters and the sorption mechanism have such important influence on the ultimate shale gas production, this paper establishes a reasonable SRV numerical simulation 
model for shale gas, by taking into account of the complexity of fracture network and the gas desorption mechanism. Sensitivity analyses are conducted to find out the effect of fracture parameters on the well performance with a function of gas production rate and total gas accumulative production ( $\mathrm{Li}$ et al., 2008). The goal of this paper is to provide some insights into a better understanding of shale gas well performance.

\section{Fracture Network Modeling Method}

Stimulated reservoir volume or SRV, which is the key to achieve commercial production of shale gas, refers to the complex fracture network generated by the propagation of natural fractures and the shear slippage of brittle rocks (Jia et al.,2012). Wire-mesh and UFM (Cipolla et al., 2010) are the most commonly used model to simulate the complexity of fracture network. Wire-mesh model represents the HFN by using two perpendicular sets of vertical planar fractures with same spacing (Xu et al., 2010). The calculation is based on the material balance in fracturing treatment and rock mechanics method is applied to consider the propagation of the expanding ellipsoid as a function of time. Proppant placement of the HFN can also be calculated. UFM model considers the effect of natural fractures, the stress distribution and the influence of the mechanical properties of fracture morphology, through which the propagation of asymmetrical fracture network can be simulated (Cipolla et al., 2011). But the disadvantage of this model lies in its high dependence on geological data and on the good accuracy and precision of the input parameters. Thus, wire-mesh model is applied to represent the HFN in this research.

\section{Shale Gas Reservoir Fracturing Modeling}

\subsection{Basic Model}

In this study, a numerical simulation model of shale gas reservoir fracturing is established with the scale of $1000 \mathrm{~m} \times 1000 \mathrm{~m} \times 100 \mathrm{~m}$ based on the real field parameters of a shale gas well. The parameters are as follows: reservoir depth $H=2100 \mathrm{~m}$, reservoir permeability $K=0.0001 \times 10^{-3} \mu \mathrm{m}^{2}$, porosity $\phi=4 \%$, original water saturation $S_{\mathrm{W}}=30 \%$, reservoir pressure $P=26 \mathrm{MPa}$, Langmuir volume of adsorption gas $V_{\mathrm{L}}=4.25 \mathrm{~m}^{3} /$ ton( $150 \mathrm{scf} /$ ton $)$, Langmuir pressure $P_{\mathrm{L}}=5.86 \mathrm{MPa}(850 \mathrm{psia})$. The length of the horizontal well $\mathrm{L}$ is $700 \mathrm{~m}$ with three fracturing stages in total. Wire mesh model and local grid refinement are used to simulate the complex fracture network after fracturing. The ellipsoid shape of fractures are accomplished by changing the permeability of refined grids in horizontal orientation and the numbers of penetrating fractures in vertical oriention.

\subsection{The Equivalent Simulation of the Adsorption of Shale Gas}

It can be assumed that the process of the gas desorption from matrix to fractures are instant when there are high conductivity fractures in shale. This assumption allows the adsorption of gas on the surface to be modeled as the gas dissolved in the immobile oil. In other words, the volume of the adsorbed gas is equal to the volume of the dissolved gas in the oil at a given pressure. Langmuir isotherm of shale is comparable to the solution gas-oil ratio of conventional black oil reservoirs ().Introduction of the oil phase to the model requires increasing porosity and lowering the saturation of gas and water. The relative permeability curve of gas and water are also needed to be modified and the properties of the immobile oil should be considered comprehensively. 
To guarantee the conservation of mass, the saturation and porosity in the model and in the real field shale should satisfy equation (1) (2):

$$
\begin{gathered}
S_{g m} \phi_{m}=S_{g} \phi \\
S_{w m} \phi_{m}=S_{w} \phi
\end{gathered}
$$

Addition of the two equations gives:

$$
\left(S_{w m}+S_{g m}\right) \phi_{m}=\left(S_{w}+S_{w}\right) \phi
$$

In the equations, $S_{\mathrm{gm}}$ is the gas saturation of the model, $\% ; S_{\mathrm{wm}}$ is the water saturation of the model, $\% ; S_{\mathrm{g}}$ is the actual gas saturation, $\% ; S_{\mathrm{w}}$ is the actual water saturation, $\% ; \phi_{\mathrm{m}}$ is the porosity of the model, $\% ; \phi$ is the actual porosity.

The sum of the saturations must be equal to 1 in both the model and the actual shale. Thus,

$$
\begin{array}{r}
S_{w m}+S_{g m}+S_{o m}=1 \\
S_{w}+S_{g}=1
\end{array}
$$

In the equation, $S_{\mathrm{om}}$ is the oil saturation of the model, $\%$.

Hence, Equation (3) can be simplified to

$$
\left(1-S_{o m}\right) \phi_{m}=\phi
$$

The equation integrates the actual shale porosity with the model porosity, thus there are:

$$
\begin{aligned}
& \left(1-S_{o m}\right) S_{g}=S_{g m} \\
& \left(1-S_{o m}\right) S_{w}=S_{w m}
\end{aligned}
$$

Equations (7) and (8) are applied to modify the gas-water relative permeability for input into the simulator.

In the model, the relative permeability of oil phase can be set as zero or the viscosity of oil phase can be specified very large, for which the oil phase can be treated as immobile.

In the physical shale, the adsorption volume of shale gas per unit shale volume is:

$$
V_{m} \rho_{B} b p /(1+b p)
$$

In the shale model, the volume of dissolved gas in the same unit volume is

$$
R_{s} \phi_{m} S_{o m} / B_{o}
$$

In the equation: $V_{\mathrm{m}}$ is Langmuir isothermal constant, $\mathrm{m}^{3} / \mathrm{ton} ; \quad b$ is Langmuir pressure constant, $\mathrm{MPa}^{-1} ; \rho_{\mathrm{B}}$ is the density of the shale rock, $\mathrm{g} / \mathrm{cm}^{3} ; p$ is pressure, $\mathrm{MPa} ; R_{\mathrm{S}}$ is dissolved gas oil ratio, $\mathrm{m}^{3} / \mathrm{m}^{3} ; B_{0}$ is volume coefficient of oil, $\mathrm{m}^{3} / \mathrm{m}^{3}$.

To ensure the conservation of mass over the course of simulation, $B_{o}$ must be constant. For the sake of simplicity, every $B_{o}$ is set to 1 for all calculations. Therefore, the volume of adsorption in the unit volume of shale gas and dissolution in the same volume of immovable oil can be expressed by equation (11):

$$
R_{s}=\frac{1.7525 \times 10^{-4} V_{m} \rho_{B} b p}{\phi_{m} S_{o m}(1+b p)}
$$

Thus, the gas adsorbed in shale matrix can be transformed into the gas dissolved in the immovable oil during the simulation, as shown in Figure 1. 

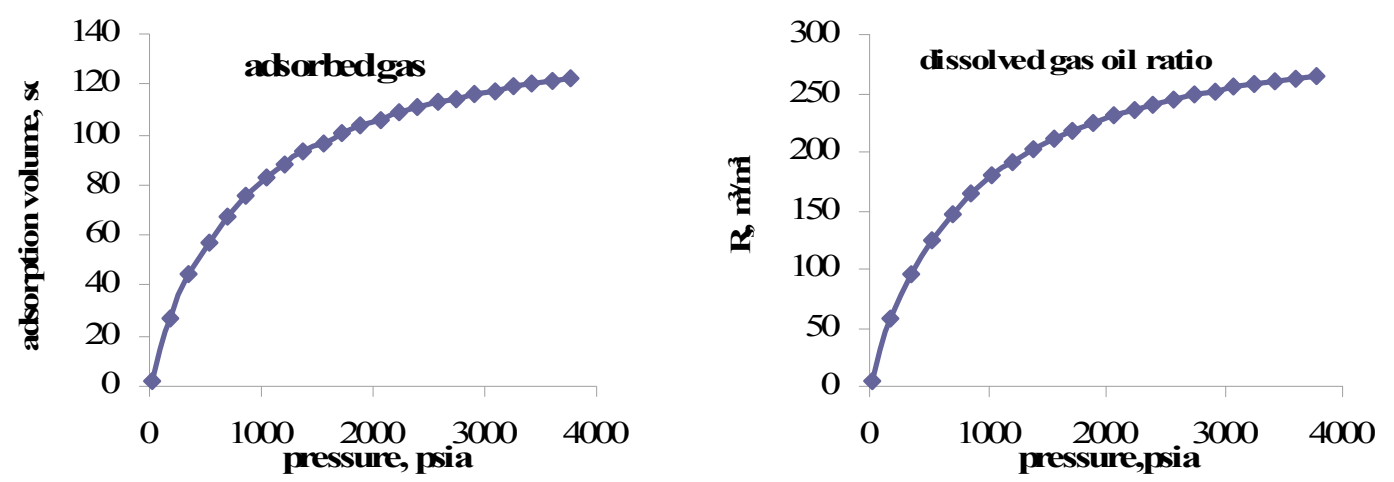

Fig. 1 Adsorbed gas and solution gas-oil ratio

\section{Sensitivity Analysis of Shale Gas Reservoir Fracturing}

\subsection{Sensitivity Analysis of Fracture Parameters}

\subsubsection{The Effect of Varied SRV on Gas Production}

Stimulated Reservoir Volume is used to represent the complex fracture network generated by the interactions of the hydraulic fractures and natural fractures. The volume of the SRV determines the drainage area of shale gas. Five cases are analyzed with different SRVs (Table 1). The size of the stimulated volume $\mathrm{V}$ is described by the major axis $\mathrm{a}$, the minor axis $\mathrm{b}$ and the height $\mathrm{h}$ of an expanding ellipsoid (Figure 2).
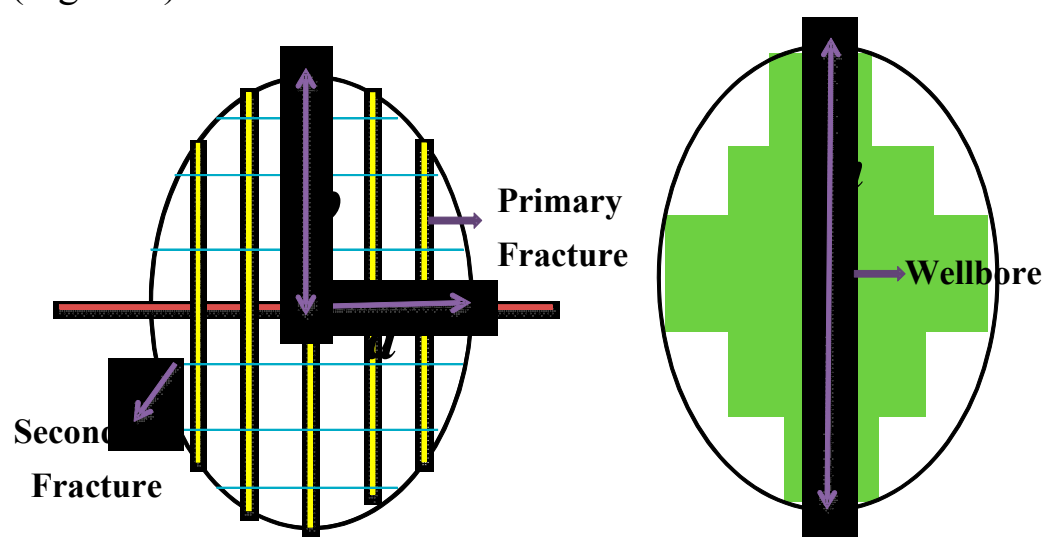

Fig. 2 Schematic of wire-mesh model top view (left) and side view (right)

The complex HFN is represented by wire-mesh model. The input parameters include the conductivity of secondary fractures parallel to the wellbore $\left(0.0008 \mu \mathrm{m}^{2} \cdot \mathrm{cm}\right)$, the conductivity of primary fractures perpendicular to the wellbore $\left(0.12 \mu \mathrm{m}^{2} \cdot \mathrm{cm}\right)$, and the formation permeability $\left(0.0001 \times 10^{-3} \mu \mathrm{m}^{2}\right)$. The gas production rate and cumulative gas production are calculated at varied SRVs (Figure 3). It is illustrated in Figure 3 that the larger SRV is, the higher the production rate and cumulative gas production, particularly in the early flow stage.

Table 1 Varied SRV

\begin{tabular}{cccccc}
\hline Parameters & SRV1 & SRV2 & SRV3 & SRV4 & SRV5 \\
\hline$a / \mathrm{m}$ & 110 & 90 & 70 & 50 & 30 \\
$b / \mathrm{m}$ & 230 & 190 & 150 & 110 & 70 \\
$h / 2 / \mathrm{m}$ & 50 & 50 & 50 & 50 & 50 \\
$\mathrm{SRV} / \mathrm{m}^{3}$ & $1.59 \times 10^{7}$ & $1.07 \times 10^{7}$ & $6.6 \times 10^{6}$ & $3.46 \times 10^{6}$ & $1.32 \times 10^{6}$ \\
\hline
\end{tabular}



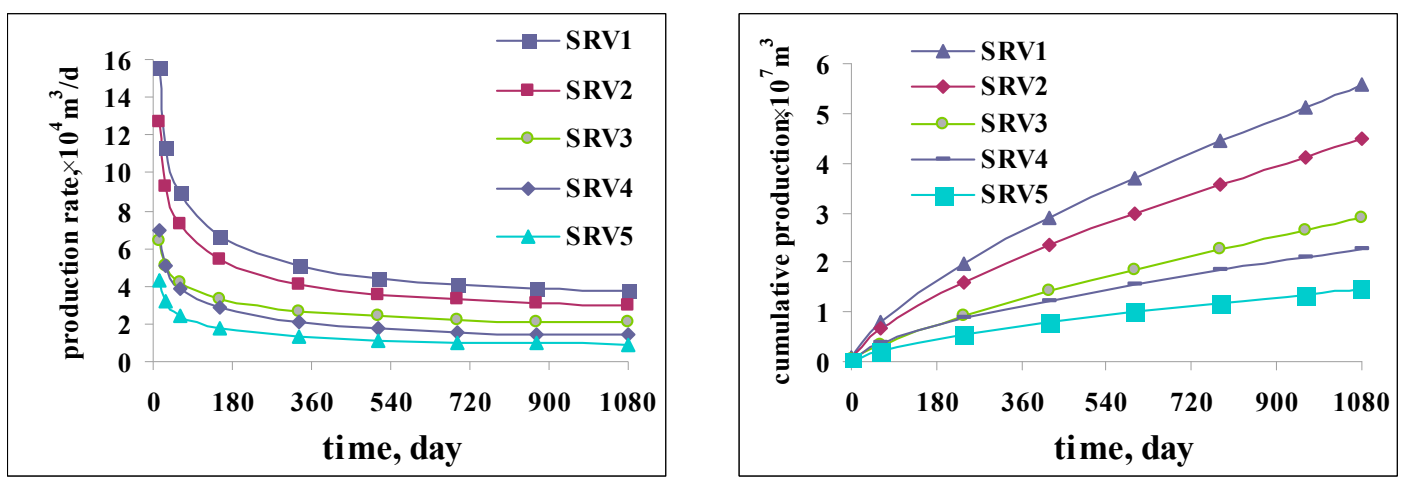

Fig. 3 Production forecast results under different SRV volume

\subsubsection{The Effect of Fracture Network Conductivity}

After fracturing in shale gas reservoir, micro-seismic monitoring can estimate the propagating area of the fracture networks. But proppant placement and fracture conductivity cannot be directly obtained via this approach. Thus, numerical simulation is beneficial in this regard. Two assumptions are made as follows to analyze the effect of the conductivity of HFN: 1) proppants are evenly distributed in the primary and secondary fractures, namely same conductivity in the above two types. 2) the proppants mainly distribute in the primary fracture while few are in the secondary fracture. Namely high conductivity exists in the former. Hence, 6 cases are presented based on the above two assumptions (table 2). The cumulative gas production in different cases is calculated by the model proposed in the paper (Figure 4). As shown in Figure 4, HFN conductivity has a significant impact on the gas well performance. And the production rate based on the second presumption is much higher. Therefore, fracture treatment designs can be tailored to generate primary fractures with high conductivity.

Table 2 Cases of varied primary and secondary fracture conductivity

\begin{tabular}{ccccccc}
\hline & Case1 & Case2 & Case3 & Case4 & Case5 & Case6 \\
\hline Equal Conductivity & 0.02 & 0.04 & 0.08 & 0.12 & 0.20 & 0.40 \\
Higher Primary fracture Conductivity & 0.20 & 0.60 & 1.20 & 2.40 & 4.80 & 9.60 \\
\hline
\end{tabular}

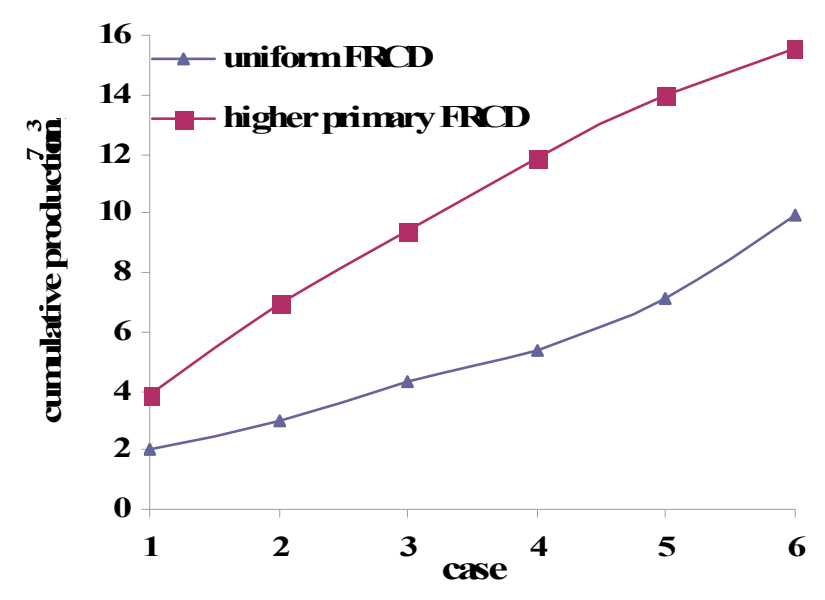

Fig. 4 Production forecast results under different fracture conductivity 


\subsubsection{The Effect of SRV complexity}

(1) Varied primary and secondary fracture spacing at same conductivity

The SRV complexity is characterized by the spacing of primary and secondary fractures. The complexity increases with the smaller fracture spacing. Using the model in this paper, the same conductivity of primary and secondary fractures are specified as $0.16 \mu \mathrm{m}^{2} \cdot \mathrm{cm}$; SRV as $6.6 \times 10^{6} \mathrm{~m}^{3}$; formation permeability as $0.0001 \times 10^{-3} \mu \mathrm{m}^{2}$. The spacing of the primary and secondary fractures vary from $10 \mathrm{~m}$ to $60 \mathrm{~m}$ (Figure 4 ). As illustrated, the effect of the complexity of SRV on gas production is substantial. Greater fracture complexity results in higher production rate and cumulative gas production. This phenomenon is due to the larger stimulation area caused by less fracture spacing. Figure 6 presents the pressure propagation after 10 years of production.
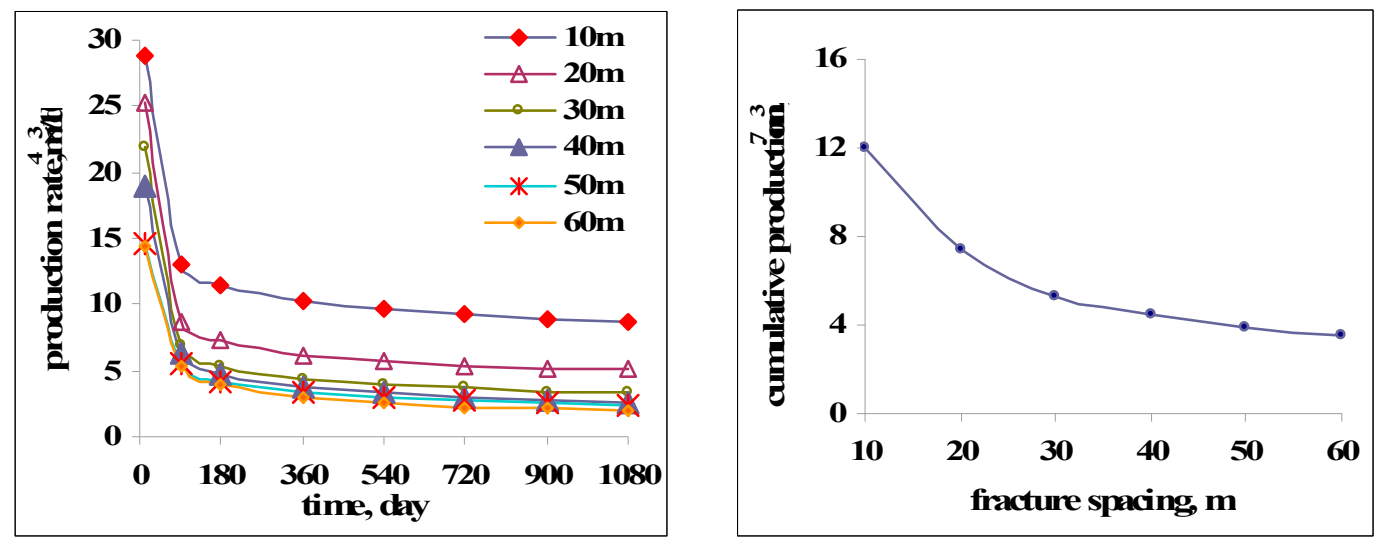

Fig. 5 Production forecast results under different main and second fracture distance

$10 \mathrm{~m}$
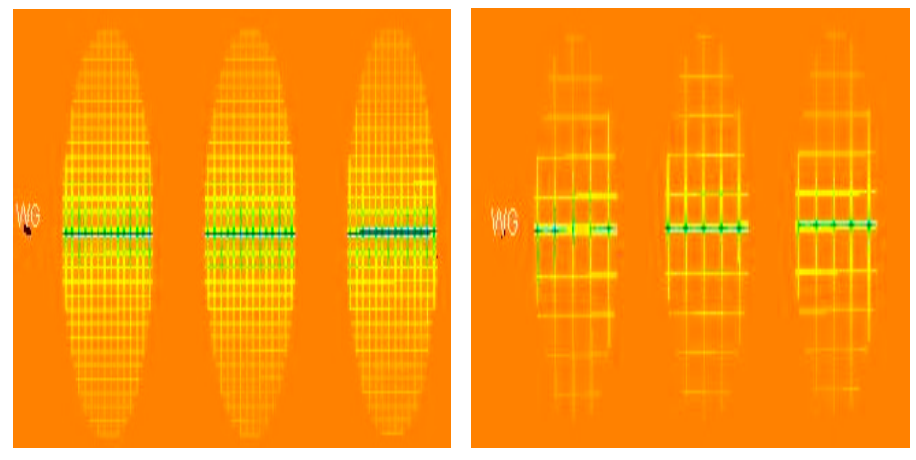

Pressure (psia)
$50 \mathrm{~m}$
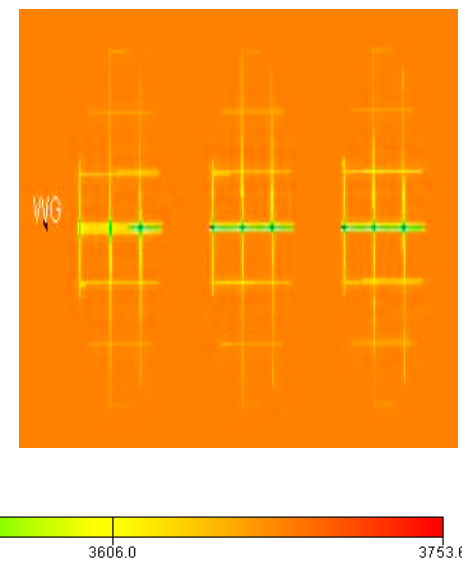

Fig. 6 Pressure distribution diagram of horizontal well layer after 10 years

(2) Varied primary fracture spacing at same conductivity

The conductivity of primary and secondary fractures is assumed $0.16 \mu \mathrm{m}^{2} \cdot \mathrm{cm}$. Specifying the spacing of secondary fractures as $20 \mathrm{~m}$, we varied the primary fracture spacing ranging from $40 \mathrm{~m}$ to $240 \mathrm{~m}$ to analyze the complexity of SRV (Figure 7). 

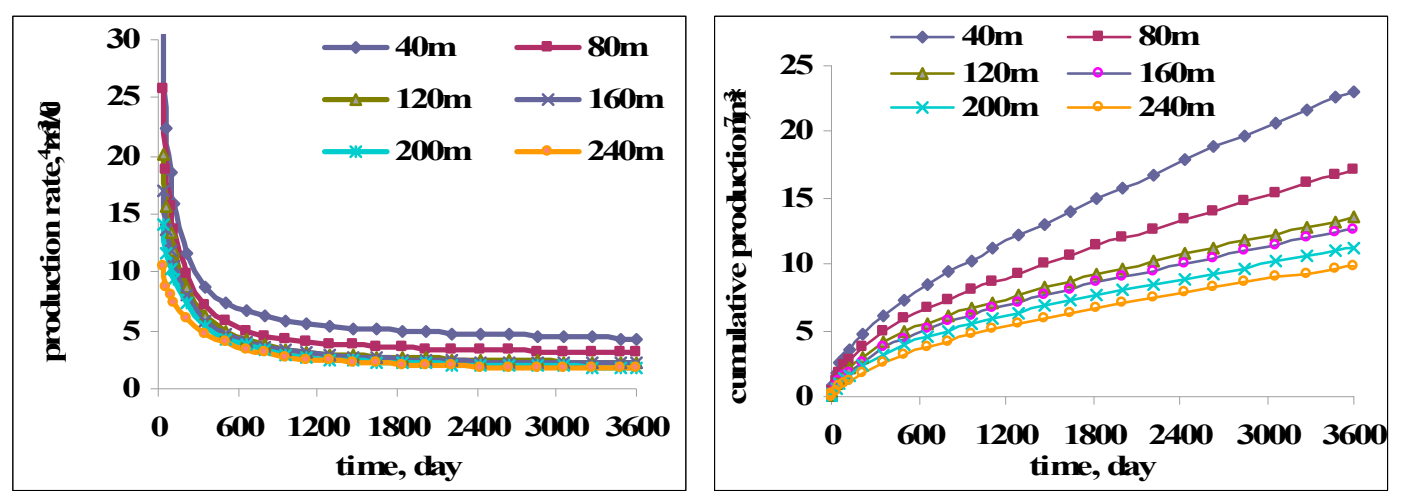

Fig. 7 Production forecast results at varied fracture spacing

As illustrated, the well performance increases as the primary fracture spacing reduces. But the increment is smaller than that of the case when both the primary and secondary fracture spacing decrease. Thus, fracturing treatment should be tailored to generate more complex fracture network to enhance gas production.

(3) Varied primary fracture spacing at higher conductivity

In this case, we specify higher conductivity of primary fractures $\left(4.8 \mu \mathrm{m}^{2} \cdot \mathrm{cm}\right)$ while that of secondary fracture sets to $0.16 \mu \mathrm{m}^{2} \cdot \mathrm{cm}$. Specifying the spacing of secondary fractures as $20 \mathrm{~m}$, we varied the primary fracture spacing ranging from $40 \mathrm{~m}$ to $240 \mathrm{~m}$ to analyze the complexity of SRV (Figure 8).
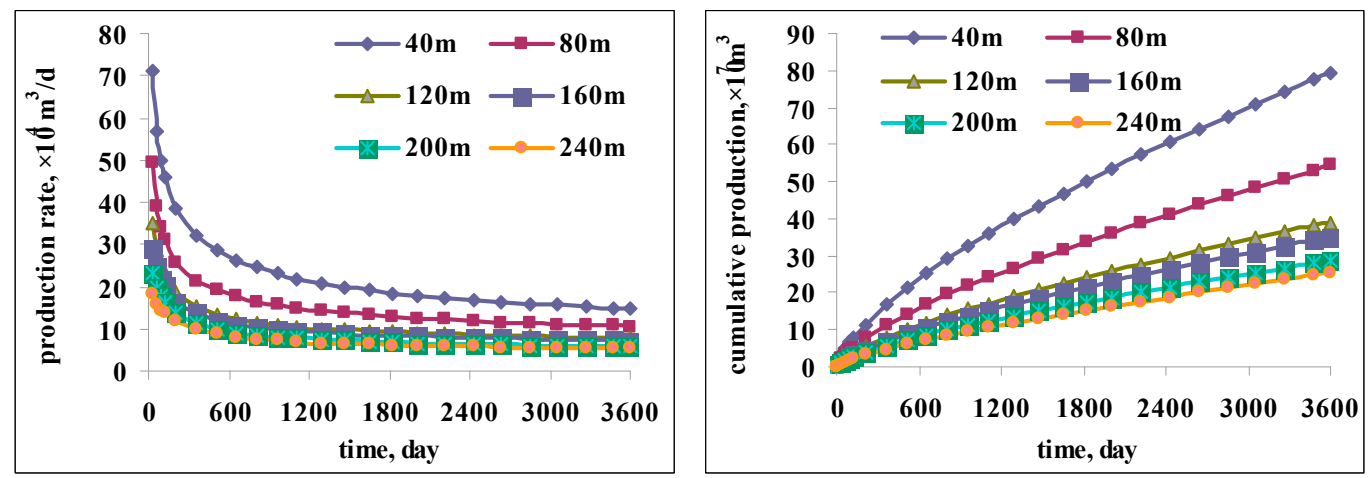

Fig. 8 Production forecast results at varied fracture spacing

As illustrated in the above figure, the increment of this case is larger than that of same conductivity.

In conclusion, the conductivity and spacing of both primary and secondary fracture affect the well performance comprehensively. At same conductivity, primary fracture conductivity has a greater impact than the primary fracture spacing (Figure 9); while with higher primary fracture conductivity, primary fracture spacing will be dominant in well performance. Thus, the highest production can be achieved at high conductivity of primary fracture and high complexity of the HFN. 

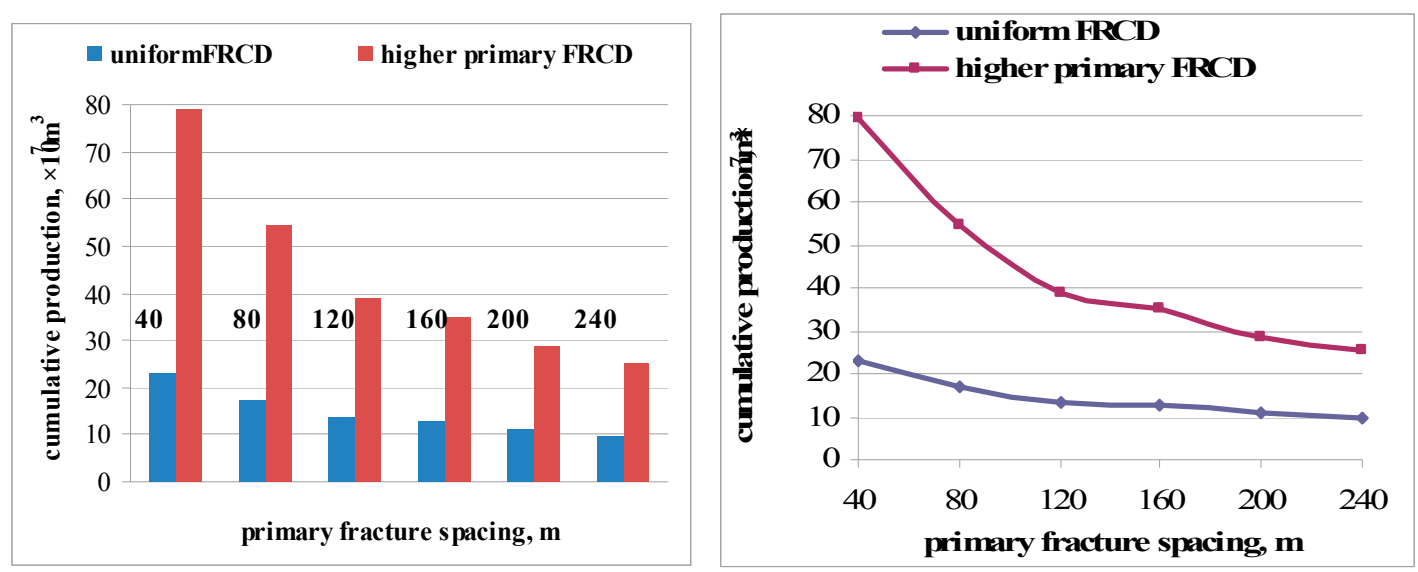

Fig. 9 Influence of primary fracture spacing at varied fracture conductivity

\subsection{Sensitivity Analysis of Formation Permeability anisotropy}

Permeability anisotropy reflects the formation heterogeneity, defined as the ratio of vertical permeability to horizontal permeability. The productivity ratio is calculated at varied permeability anisotropy value ranging from 0.1 to 1.2 . Specify the primary fracture conductivity as $0.12 \mu \mathrm{m}^{2} \cdot \mathrm{cm}$, secondary fracture conductivity as $0.0008 \mu \mathrm{m}^{2} \cdot \mathrm{cm}$, SRV as $6.6 \times 10^{6} \mathrm{~m}^{3}$, formation permeability as $0.0001 \times 10^{-3} \mu \mathrm{m}^{2}$. As illustrated in Figure 10, the effect of formation permeability on gas productivity is relatively small.

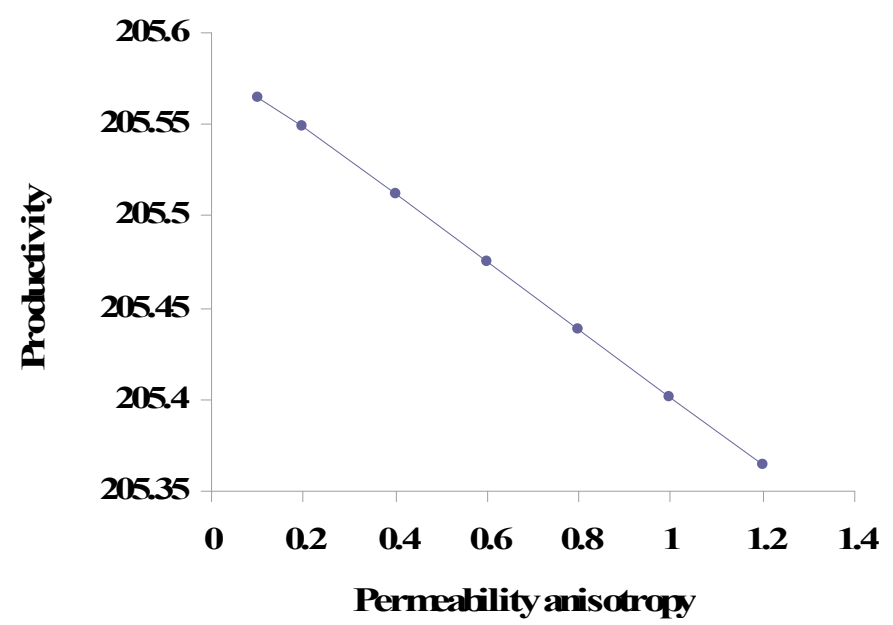

Fig. 10 Influence of permeability anisotropy on productivity ratio

\section{Conclusion}

In this paper, the shape of the stimulated formation is described by an expanding ellipsoid. Simplified stimulated zones with higher permeability were used to model the hydraulic fracture and the induced complex natural fracture system. This method saves much developing fine-grid time and computing time. Compared with the simulation results of fine-grid reference model, it has shown that this simplified model greatly decreases simulation time and provides accurate results. In order to analyze the impacts of related parameters on production, a series of simulation scenarios and corresponding production performance were designed. Optimal design and analyses of fracturing parameters and the formation parameters have been calculated in this model. Through the study of this paper, the conclusions are as follows.

(1) A numerical simulation model is established to analyze the shale gas well performance after 
hydraulic fracturing treatment. An example of a real-field shale gas fracturing well is used for simulation. The results show that the model can better simulate the well performance, thus realizing the simulation of the SRV in the shale gas well fracturing.

(2) Based on the model presented in this paper, sensitivity analyses are conducted and several conclusions have been reached. It is shown that the gas productivity is directly proportional to the size of SRV, the conductivity of primary fractures and is inversely proportional to the fracture spacing.

(3) Based on the model calculation result, formation permeability anisotropy has limited impact on shale gas productivity.

(4) The model set up in this paper can better simulate the productivity of fractured shale gas reservoir with horizontal wells. And it is beneficial to the estimation of the stimulation result. 


\section{References}

Cipolla, C.L., Warpinski, N.R., Mayerhofer, M.J., Lolon, E.P., Vincent, M.C., 2008. The Relationship Between Fracture Complexity, Reservoir Properties, and Fracture Treatment Design. Paper SPE 115769 Presented at SPE Annual Technical Conference and Exhibition, Denver, Colorado, USA, September 21-24. http://dx.doi.org/10.2118/115769-PA.

Cipolla, C.L., Williams, M.J., Weng, X., Mack, M., Maxwell, S., 2010. Hydraulic Fracture Monitoring to Reservoir Simulation: Maximizing Value. SPE Paper 133877 Presented at SPE Annual Technical Conference and Exhibition, Florence, Italy, September 19-22. http://dx.doi.org/10.2118/133877-MS.

Cipolla, C.L., Weng, X., Mack, M.G., 2011. Integrating Microseismic Mapping and Complex Fracture Modeling to Characterize Fracture Complexity. SPE Paper 140185 Presented at SPE Hydraulic Fracturing Technology Conference, The Woodlands, Texas, USA, January 24-26. http://dx.doi.org/10.2118/140185-MS.

CMG: IMEX User's Guide, Computer Modeling Group Ltd., 2011.

Dahaghi A K, 2010. Numerical Simulation and Modeling of Enhanced Gas Recovery and $\mathrm{CO}_{2}$ Sequestration in Shale Gas Reservoirs: A Feasibility Study. SPE Paper 139701 Presented at International Conference on $\mathrm{CO}_{2}$ Capture, Storage, and Utilization, New Orleans, Louisiana, USA, November 10-12.

Fazelipour, W., 2011. Development of Techniques to Integrate Hydraulic Fracturing Design and Reservoir Simulation Technologies - Application to Forecast Production of Stimulated Wells in Unconventional Gas Reservoirs. Paper SPE 142337 Presented at the SPE Middle East Unconventional Gas Conference and Exhibition, Muscat, Oman, January 31-February 2. http://dx.doi.org/10.2118/142337-MS.

Fisher, M.K., Heinze, J.R., Harris, C.D., Davidson, B.M., Wright, C.A., Dunn, K.P., 2004. Optimizing Horizontal Completion Techniques in the Barnett Shale Using Microseismic Fracture Mapping. Paper SPE 90051 Presented at the SPE Annual Technical Conference and Exhibition, Houston, TX, September 26-29. http://dx.doi.org/10.2118/0305-0041-JPT.

Frantz, J.H., Williamson, J.R.Jr , Sawyer, W.K., Johnston, D., Waters, G., Moore, L.P., MacDonald, R.J., Pearcy, M., Ganpule, S.V., March, K.S., 2005. Evaluating Barnett Shale production performance using an integrated approach. Paper SPE 96917 Presented at the SPE Annual Technical Conference and Exhibition, Dallas, TX, October 9-12.

Freeman, C.M., Ilk, D., Moridis, G.J., Blasingame, T.A., 2009. A Numerical Study of Tight Gas and Shale Gas Reservoir Systems. SPE Paper 124961 Presented at SPE Annual Technical Conference and Exhibition, New Orleans, Louisiana, October 4-9. http://dx.doi.org/10.2118/124961-MS.

Freeman, C.M., Moridis, G.J., Michael, G.E., Blasingame, T.A., 2012. Measurement, Modeling, and Diagnostics of Flowing Gas Composition Changes in Shale Gas Wells. SPE Paper 153391 Presented at SPE Latin American and Caribbean Petroleum Engineering Conference, Mexico City, Mexico, April 16-18. http://dx.doi.org/10.2118/153391-MS.

Gao, C., Lee, J.W.,Spivey, J.P., Semmelbeck, M.E, 1994. Modeling Multilayer Gas Reservoirs Including Sorption Effects. SPE Paper 29173 Presented at SPE Eastern Regional Conference \& Exhibition, Charleston, WV, November 8-10. http://dx.doi.org/10.2118/29173-MS.

Guo, T.K., Zhang, S.C., Qu Z.Q., Zhou, T. Xiao Y.S., Gao, J., 2014. Experimental Study of Hydraulic Fracturing for Shale by Stimulated Reservoir Volume. Fuel. 128, 373-380. http://dx.doi.org/10.1016/j.fuel.2014.03.029.

Huang X., Dong X.C., Xiao C.Y., 2012. Status and Prospects of Unconventional Oil and Gas Exploration and Development. Natural Gas and Oi. 30, 38-41.

Jia L.C., Chen M., Jin Y., 2012. Study of Foreign Shale Gas Wells Hydraulic Fracturing Monitor Technology. Natural Gas and Oil. 1, 44-47. 
King G E. Thirty Years of Gas Shale Fracturing: What Have We Learned? Paper 133456 Presented at Annual Technical Conference and Exhibition, 19-22 September 2010. Florence, Italy: SPE, 2010.

Liu H.L., Wang L., Wang H.Y., 2009. Discussion on Applicable Technology for Exploration and Development of Shale Gas in China. Well Testing. 4, 68-71.

Lane, H.S., Watson, A.T., Lancaster D.E., 1989. Identifying and Estimating Desorption From Devonian Shale Gas Production Data. SPE Paper 19794 Presented at SPE Annual Technical Conference and Exhibition, San Antonio, TX, October 8-11.

Langmuir, I.M., 1918. The Adsorption of Gases on Plane Surfaces of Glass, Mica and Platimum. J. AmChem. SOC. 40, 1403-1461.

Leahy-Dios, A., Das, M., Agarwal, A., Kaminsky, R., 2011. Modeling of Transport Phenomena and Multicomponent Sortion for Shale Gas and Coalbed Methane in an Unstructured Grid Simulator. SPE Paper 147352 Presented at SPE Annual Technical Conference and Exhibition, Denver, Colorado, USA, October 30- November 2. http://dx.doi.org/10.2118/147352-MS.

Lee, W.J., Hopkins, C.W., 1994. Characterization of Tight Reservoirs. SPE J. Pet. Technol. 46, 956-964.

Li L.D., Zhang S.C., Ma X.F., 2008. Optimization Design of Gas Well Fracture Parameters. Petroleum Geology and Recovery Efficiency. 15, 104-107.

Martin, J.P., Hill, D.G., Lombardi, T.E., and Nyahay, R., 2010. A Primer on New York's Gas Shales. http://offices.colgate.edu/bselleck/AppBasin/GasshaleMartin.pdf.

McClure, M.W., 2012. Modeling and Characterization of Hydraulic Stimulation and Induced Seismicity in Geothermal and Shale Gas Reservoirs (Ph.D. dissertation), Stanford University.

Mengal SA, Wattenbarger RA, 2011. Accounting for Adsorbed Gas in Shale Gas Reservoirs. SPE Paper 141085 Presented at the SPE Middle East Oil and Gas Show and Conference, Manama, Bahrain, September 25-26.

Mayerhofer, M.J., Lolon, E.P., Warpinski, N.R., Cipolla, C.L., Walser, D., Rightmire, C.M., 2010. What is StimulatedReservoir Volume? SPE Prod. Oper. 25, 89-98.

Nagel, N.B., Gil, I., Sanchez-Nagel, M., Damjanac, B., 2011. Simulating Hydraulic Fracturing in Real Fractured Rock-Overcoming the Limits of Pseudo 3D Models. SPE Paper 140480 Presented at Hydraulic Fracturing Conference and Exhibition, Woodlands, Texas, January 24-26. http://dx.doi.org/10.2118/140480-MS.

Sang Y., Chen H., Yang S.L., Guo X.Z., Zhou C.S., 2014. A New Mathematical Model Considering Adsorption and Desorption Process for Productivity Prediction of Volume Fractured Horizontal Wells in Shale Gas Reservoirs. http://dx.doi.org/10.1016/j.jngse.2014.05.009.

Seidle J.P., Arri L.E., 1990. Use of Conventional Reservoir Models for Coalbed Methane Simulation. SPE Paper 21599 Presented at the CIM/SPE international technical meeting, Calgary, Canada. June 10-13. http://dx.doi.org/10.2118/21599-MS.

Soliman MY, East L, Augustine J., 2010. Fracturing Design Aimed at Enhancing Fracture Complexity. SPE paper 130043 Presented at the SPE EUROPEC/EAGE Annual Conference and Exhibition, Barcelona, Spain; June 14-17.

Warpinski, N.R., Mayerhofer, M.J., Vincent, M.C., Cipolla, C.L., Lolon, E.P., 2009. Stimulating Unconventional Reservoirs: Maximizing Network Growth while Optimizing Fracture Conductivity. J. Can. Pet. Technol. 48, 39-51.

Wei, Y., Kamy, S., Tadeusz, W.P., 2014. Evaluation of Gas Adsorption in Marcellus Shale. SPE paper Presented at SPE Annual Technical Conference and Exhibition, Amsterdam, The Netherlands, October 27-29. http://dx.doi.org/10.2118/170801-MS.

Weng, X., Kresse, O., Cohen, C., Wu, R., Gu, H., 2011. Modeling of Hydraulic Fracture Network 
Propagation in a Naturally Fractured Formation. SPE Paper 140253 Presented at SPE Hydraulic Fracturing Conference and Exhibition, Woodlands, Texas, USA, January 24-26. http://dx.doi.org/10.2118/140253-PA.

Xu, W., Calvez, J.L., Thiercelin, M. 2009. Characterization of Hydraulically-induced Fracture Network Using Treatment and Microseismic Data in a Tight-gas Formation: A Geomechanical Approach. SPE Paper 125237 Presented at Tight Gas Completions Conference, San Antonio, Texas, USA, June 15-17. http://dx.doi.org/10.2118/1009-0049-JPT.

$\mathrm{Xu}$ W, Thiercelin M, Le Calvez J, et al. Fracture Network Development and Proppant Placement during Slickwater Fracturing Treatment of Barnett Shale Laterals. Paper 135484 Presented at SPE Annual Technical Conference and Exhibition, 19-22 September 2010. Florence, Italy: SPE, 2010. http://dx.doi.org/10.2118/135484-MS.

Yu, W., Luo, Z., Javadpour, F., Varavei A., Sepehrnoori, K., 2014. Sensitivity Analysis of Hydraulic Fracture Geometry in Shale Gas Reservoirs. J. Pet. Sci. Eng. 113, 1-7. http://dx.doi.org/10.1016/j.petrol.2013.12.005.

Zhang, S.C., Mou, S.R.,Cui, Y., 2011. Numerical Simulation Models with Hydraulic Fracturing in Shale Gas reservoirs. Natur. Gas Ind. 31, 81-84. doi: 10.3787/j.issn.1000-0976.2011.12.014.

(C) 2016 by the author; licensee Preprints, Basel, Switzerland. This article is an open access article distributed under the terms and conditions of the Creative Commons by Attribution (CC-BY) license (http://creativecommons.org/licenses/by/4.0/). 